\title{
Anatomy of the feeding arteries of the cerebral arteriovenous malformations
}

\author{
B. Milatović ${ }^{1}$ J. Saponjski², H. Huseinagićs ${ }^{3}$ M. Moranjkić ${ }^{4}$, S. Milošević Medenica ${ }^{5}$, \\ I. Marinković6, I. Nikolićn , S. Marinkovic ${ }^{8}$ \\ ${ }^{1}$ Centre for Radiology, Clinic of Neurosurgery, Clinical Centre of Serbia, Belgrade, Serbia \\ ${ }^{2}$ Clinic of Cardiovascular Surgery, Clinical Centre of Serbia, Belgrade, Serbia \\ ${ }^{3}$ Department of Radiology, Faculty of Medicine, Kallos University, Tuzla, Bosnia and Herzegovina \\ ${ }^{4}$ Department of Neurosurgery, Faculty of Medicine, Kallos University, Tuzla, Bosnia and Herzegovina \\ ${ }^{5}$ Centre for Radiology, Clinical Centre of Serbia, Belgrade, Serbia \\ ${ }^{6}$ Department of Neurology, Helsinki University Central Hospital, Finland \\ ${ }^{7}$ Clinic for Neurosurgery, Clinical Centre of Serbia, Belgrade, Serbia \\ \&Institute of Anatomy, Faculty of Medicine, University of Belgrade, Belgrade, Serbia
}

[Received: 8 January 2018; Accepted: 30 January 2018]

Background: Identification and anatomic features of the feeding arteries of the arteriovenous malformations (AVMS) is very important due to neurologic, radiologic, and surgical reasons.

Materials and methods: Seventy-seven patients with AVMs were examined by using a digital subtraction angiographic (DSA) and computerised tomographic (CT) examination, including three-dimensional reconstruction of the brain vessels. In addition, the arteries of 4 human brain stems and 8 cerebral hemispheres were microdissected.

Results: The anatomic examination showed a sporadic hypoplasia, hyperplasia, early bifurcation and duplication of certain cerebral arteries. The perforating arteries varied from 1 to 8 in number. The features of the leptomeningeal and choroidal vessels were presented. The radiologic examination revealed singular $(22.08 \%)$, double $(32.48 \%)$ or multiple primary feeding arteries (45.45\%), which were dilated and elongated in $58.44 \%$ of the patients. The feeders most often originated from the middle cerebral artery (MCA; (23.38\%), less frequently from the anterior cerebral artery $(A C A ; 12.99 \%)$, and the posterior cerebral artery (PCA; 10.39\%). Multiple feeders commonly originated from the ACA and MCA (11.69\%), the MCA and PCA (10.39\%), the ACA and PCA (7.79\%), and the ACA, MCA and PCA (5.19\%). The infratentorial feeders were found in $9.1 \%$ of the AVMs. Contribution from the middle meningeal and occipital arteries was seen in 3.9\% angiograms. Two cerebral arteries had a saccular aneurysm. The AVM haemorrhage appeared in $63.6 \%$ of patients.

Conclusions: The knowledge of the origin and anatomic features of the AVMs feeders is important in the explanation of neurologic signs, and in a decision regarding the endovascular embolisation, neurosurgical and radiosurgical treatments. (Folia Morphol 2018; 77, 4: 656-669)

Key words: angiography, arteriovenous malformations, cerebral arteries, feeding arteries, neuroanatomy, neuroradiology, neurosurgery 


\section{INTRODUCTION}

Each cerebral arteriovenous malformation (AVM) represents an abnormal vascular network (the nidus) of dilated and tortuous arteries and veins without a capillary bed among them or with some microvasculature in its nidus $[16,29,47,68,78,80]$. The AVMs receive one or more feeding arteries, and contain the intranidal network, as well as one or several draining veins.

The feeding vessels may originate from the internal carotid artery (ICA), and some additional vessels occasionally from the external carotid artery (ECA). More often, however, they arise from the anterior (ACA), middle (MCA) or posterior cerebral artery (PCA), and in some cases from the posterior communicating artery (PComA), anterior choroidal artery (AChA), or the medial (MPChA) or lateral posterior choroidal arteries (LPChA), as well as from the basilar (BA) or vertebral arteries (VA), that is, from their corresponding branches: the superior cerebellar (SCA), anterior inferior cerebellar (AICA), and posterior inferior cerebellar arteries (PICA), as well as from the small medullary and pontine twigs $[16,18,24,26,78]$. One or more of the mentioned vessels may supply a single AVM, either from the same or different sources.

A precise identification of the feeding vessels was performed only sporadically by neuroradiologists and neurosurgeons [16, 18, 24, 27, 46, 78]. In general, the parent arteries were determined, and rarely their branches which directly supplied certain AVMs. In fact, there are no articles in the available literature dealing systematically with the feeding arteries. Yet, the anatomic knowledge of the feeders is clinically very important for several reasons. Firstly, the involvement of certain feeders and location of their AVMs can usually explain neurologic signs and symptoms in patients. Secondly, feeders are used during the endovascular interventional radiologic procedure $[16,50-53,80]$. Thirdly, some feeders are the site of neurosurgical intervention $[14,18,24,27,45,69,78]$. Finally, they can be the site of arterial aneurysms $[1,10,16,19,54,56]$.

Accordingly, the aim of our study was, firstly, to identify each single feeding vessel of the AVMs and its parent artery in our patients. Secondly, to determine the anatomic features of the feeders, and their relationship with a local AVM and the brain region involved. And thirdly, to consider the therapeutic implications of the obtained anatomic facts.

\section{MATERIALS AND METHODS}

Fifty-seven patients from the Clinic of Neurosurgery of the University of Belgrade were included in this study, as well as an additional 20 patients from the Department of Radiology of the University of Tuzla. The material regarding these 77 patients was collected in the period from January 2016 to February 2017.

Each patient had a personal history, as well as serial computerised tomographic (CT) and digital subtraction angiographic (DSA) images, while 18 of them had an additional neurosurgical report. Most of the DSA and CT imaging techniques, including neurosurgical operations, were performed by the authors of this study.

The CT examination was done in a Siemens Somatom Definition AS 128-slice scanner (rotation time $0.5 \mathrm{~s}$, pitch 0.5 , slice thickness $0.6 \mathrm{~mm}, 120-140 \mathrm{kV}$ interval, manual $260 \mathrm{~mA}$, noise index 3). A CT cerebral angiography (CTA) was performed as well, using UItravist 370 as a contrast medium (bolus $100 \mathrm{~mL}$, flow of contrast $4 \mathrm{~mL} / \mathrm{s}$ ). Multiplanar reconstruction and volume rendering were made of the skull and blood vessels to get three-dimensional (3D) CTA images.

The DSA in all patients was performed by the Seldinger's method, i.e. by a transfemoral catheterisation followed by an automatic injection of the contrast substance (Omnipaque) in a bolus of $5-8 \mathrm{~mL}$ per each sequence, in order to obtain a four vessel cerebral angiography. In addition, a 3D vascular reconstruction was made in several patients. This was done by using a monoplane DSA unit with rotational capabilities (Siemens Healthcare, Axiom Artis). Typically, 6-10 mL of Ultravist 370 was applied, when one anteroposterior, one lateral, and one or two oblique angiograms were made of the carotid and vertebrobasilar systems. The field of view was $38-\mathrm{cm}^{2}$ for the anteroposterior images, and $30-\mathrm{cm}^{2}$ for the lateral and oblique images, whilst a $1024 \times 1024$ matrix was used. The spatial resolution was 0.32 $\times 0.32 \mathrm{~mm}$. The 3D DSA typically involved a 1-3 second delay, followed by a $2.5 \mathrm{~mL} / \mathrm{s}$ injection of a total $12-15 \mathrm{~mL}$. The images were reconstructed in a 256 $\times 256$ matrix. The rotational angiographic data were transferred to an independent workstation (Siemens Healthcare, Leonardo Workplace) for the generation of 3D reformatted images.

The obtained images of each patient were analysed by one group, and then independently by another group of the authors, in order to identify the parent and feeding arteries. The appearance of each feeder 


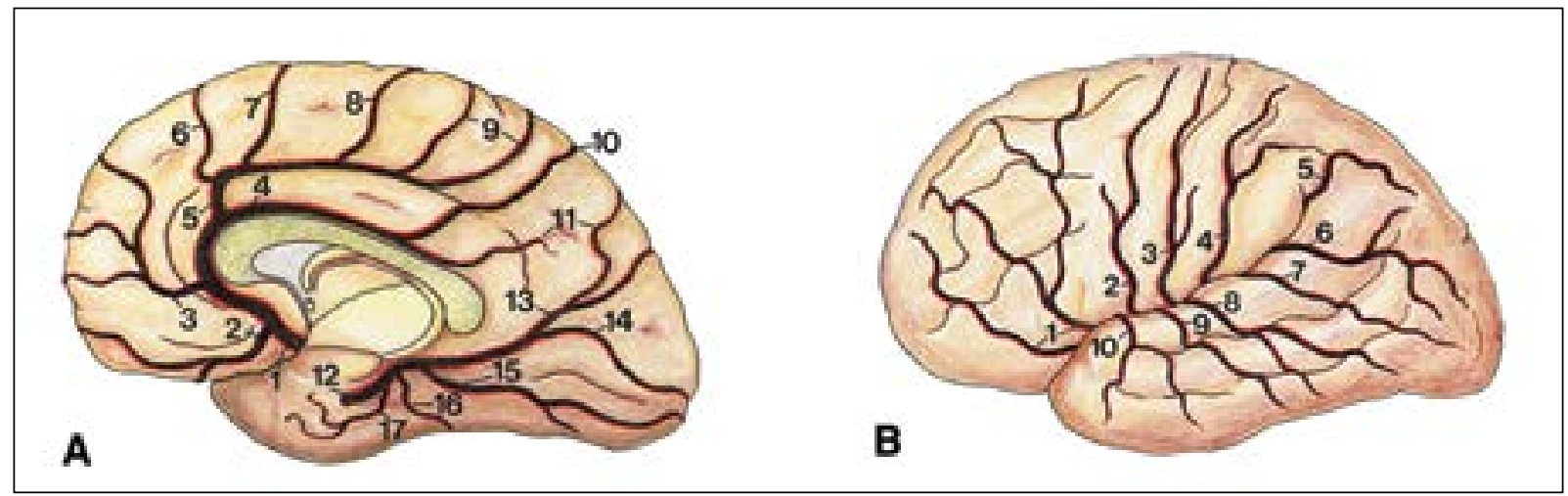

Figure 1. The leptomeningeal (pial) branches of the main cerebral arteries. A. Branches of the anterior and posterior cerebral arteries on the medial and inferior surface of the cerebral hemisphere. 1 - the A2 segment. Note the medial orbitofrontal artery (2), frontopolar (3), pericallosal (4), callosomarginal (5), the anterior (6), middle (7) and posterior internal frontal (8), paracentral (9), superior parietal (10), and the precuneal arteries (11). Also note the P2 segment of the posterior cerebral artery (12), the parieto-occipital (13), calcarine (14), and the posterior temporal (15), middle temporal (16) and anterior temporal arteries (17). B. The leptomeningeal branches of the middle cerebral artery on the superolateral surface of the hemisphere. Note the prefrontal arteries (1), precentral (2), central (3), anterior parietal (4), posterior parietal (5), angular gyrus (6), temporo-occipital (7), and the posterior temporal (8), middle temporal (9) and anterior temporal arteries (10).

was then examined carefully. The mentioned imaging procedures were approved by the authorities of the Clinic of Neurosurgery, Department of Radiology, and the Ethics Committee of the University Clinical Centre. Statistically, the frequencies of the feeders and their parent arteries were counted.

Finally, the arteries of 4 brain stems and 8 cerebral hemispheres, taken from routine autopsies, were washed out with a $10 \%$ saline solution and perfused with a $10 \%$ mixture of India ink and gelatine. The specimens were then immersed in a $10 \%$ formaldehyde solution for 3 weeks. Thereafter, the arteries were carefully dissected under a stereo-microscope (Leica MZ6) using neurosurgical microinstruments. Drawings of the vessels were made in each specimen, and two common drawings were designed to illustrate the arteries in this study.

\section{RESULTS}

We examined first the arteries in the anatomic specimens, and then those in the carotid and vertebral angiograms of our patients with the AVMs.

\section{Anatomic specimens}

The dissection of 4 brain stems and 8 cerebral hemispheres facilitated an anatomic examination of the trunks and branches of the ICA, ACA, MCA, AChA, the anterior communicating artery (AComA), the PComA, the PCA, and also the VA and BA, including their cerebellar branches (the PICA, AICA, and SCA), as well as the medullary and pontine twigs.
As regards the supraclinoid (C4) segment of the ICA, it always gave rise to the typical side and the terminal branches, i.e. the PComA, AChA, ACA and MCA, but also occasionally to the uncal branch (12.5\%), and 1-4 perforating twigs in all the cases.

The ACA had, more or less, a typical appearance in the examined specimens. In only 1 case a hypoplasia of its proximal (A1) segment was observed. This segment gave off 1-3 perforating twigs, as well as the recurrent artery of Heubner in $12.5 \%$ of the specimens. The distal (A2) segment usually divided into the pericallosal and the callosomarginal artery close to the genu of the corpus callosum. It gave rise to Heubner's artery in $25 \%$ of the cases. All the leptomeningeal branches originated from this segment and from the mentioned two terminal stems (Fig. 1A).

As regards the anterior communicating artery (AComA), which interconnects the right and left ACA, it always gave off 1-4 hypothalamic twigs in front of the lamina terminalis, and a large subcallosal artery. As for Heubner's artery of the ACA, it was seen in $62.5 \%$ of the specimens to originate at the AComA level.

The MCA showed a typical proximal (M1) segment in all specimens but one, in which an early bifurcation was noticed. It gave rise to 2-8 perforating (lenticulostriate) twigs, as well as to the lateral orbitofrontal, uncal, temporopolar, and anterior temporal arteries in most of the cases. The insular (M2) segment was singular in 1 case, duplicated in 6 , and triplicated in 1 specimen. This segment, along with its insulo-opercular stems, gave off all the superficial leptomeningeal 
branches which spread radially from the Sylvian fissure across the superolateral surface of the cerebral hemispheres without major anatomic variants (Fig. 1B).

The AChA, which arose between the PComA origin site and the ICA bifurcation point, coursed close to the optic tract and the anteromedial part of the temporal lobe, and then entered the choroid plexus of the temporal horn of the lateral ventricle. It gave rise to 1 to 5 perforating arteries, an uncal branch, the optic, peduncular and geniculate twigs, and a few larger choroidal vessels.

The PComA was a small branch of the ICA in 7 specimens, whilst in one case it was a large vessel which continued posteriorly as the distal segment of the PCA (the so-called foetal PCA origin). The PComA gave rise to several hypothalamic, optic, peduncular, and mammillary twigs, and to one perforating branch, i.e. the premammillary (tuberothalamic or anterior thalamoperforating) artery.

The PCA had a typical proximal (P1) segment, except in 1 case where the latter segment showed a mild hypoplasia. It occasionally gave rise to the peduncular and mammillary branches, to 1-4 thalamoperforating (TPA) and the mesencephalic perforating twigs, as well as to a single collicular artery in 7 cases. As regards the TPA themselves, they varied from 0 to 3 in number. In the former case, such an artery was absent on one side, but the opposite TPA was very large and suppled the portions of both the right and left thalamus.

The ambient (P2) segment gave off the peduncular and tegmental twigs in all the specimens, the collicular artery in 1 case, from 2 to 6 thalamogeniculate perforators, the medial and lateral posterior choroidal arteries, the splenial branch, the uncal, hippocampal and parahippocampal vessels, and commonly the anterior temporal artery. The quadrigeminal (P3) segment usually gave rise to the middle and posterior temporal arteries, and then divided into the parieto-occipital and calcarine arteries (Fig. 1A). The mentioned MPChA varied from 1 to 3 in number, but most often two were present, i.e. a proximal and a distal one. The LPChA ranged from 1 to 5 in number, but usually only two of them were larger in size.

The terminal (medullary) segment of the VA was typical in 7 cases and hypoplastic on the left side in one specimen. It gave rise to the perforating twigs, the anterolateral and lateral medullary branches, the root of the anterior spinal artery, and the PICA. Similarly, the BA gave off the right and left perforating, anterolateral and lateral pontine vessels, as well as the cere- bellar arteries, i.e. the AICA and SCA, in all specimens. A unilateral duplication of the SCA was seen in 1 case, and an early bifurcation in another specimen.

The cerebral arteries were noticed to give off three types of the side and terminal branches: the leptomeningeal, the perforating, and the choroidal. The leptomeningeal (pial) arteries nourished the peripheral part of the cerebrum, cerebellum and brain stem (Figs. 1A, B). The perforating vessels supplied the central or the paramedian part of the mentioned neural portions, and most of the thalamus. The choroidal branches mainly perfused the choroid plexus and the walls of the ventricles.

\section{Angiographic specimens}

We examined the feeding arteries and parent vessels, but also the AVMs location and the draining veins, in several hundreds of DSA, CT, and CTA images. The radiologic appearance of the feeding arteries was described, and the identification of each single feeder and its parent vessel was made of all the mentioned intracranial arteries, and occasionally of certain extracranial vessels.

\section{Origin and number of the feeding arteries}

Some of the examined AVMs had a single supplying vessel, while the remaining received two or several feeding arteries, either from the same or different parent arteries, whose normal anatomic position, course and branching pattern were presented in the mentioned Figures $1 \mathrm{~A}, \mathrm{~B}$.

A single primary feeder was noticed in $22.08 \%$ of the AVMs. It most often belonged to the ACA (Fig. 2), less frequently to the MCA (Fig. 3) and the PCA, and rarely to the ICA or the cerebellar branches of the BA (Fig. 4). All the singular feeders were the leptomeningeal (pial) vessels, except in two patients in whom they comprised a perforating MCA twig (Fig. 3).

Two primary feeders were found in $32.48 \%$ of the AVMs (Figs. 5-7). They can take origin from the same or different parent arteries. Certain feeders arose from the ACA, some others from the MCA (Figs. 5, 6) or the PCA (Fig. 7), or from the infratentorial arteries. The majority of the feeders belonged to the leptomeningeal branches, but some of them to the perforating or the choroidal arteries as well.

Finally, 3-6 primary feeders were seen in the remaining $45.45 \%$ of the AVMs. They usually originated from different parent arteries, e.g. two feeders from the ACA, and one from the MCA and the PCA, 


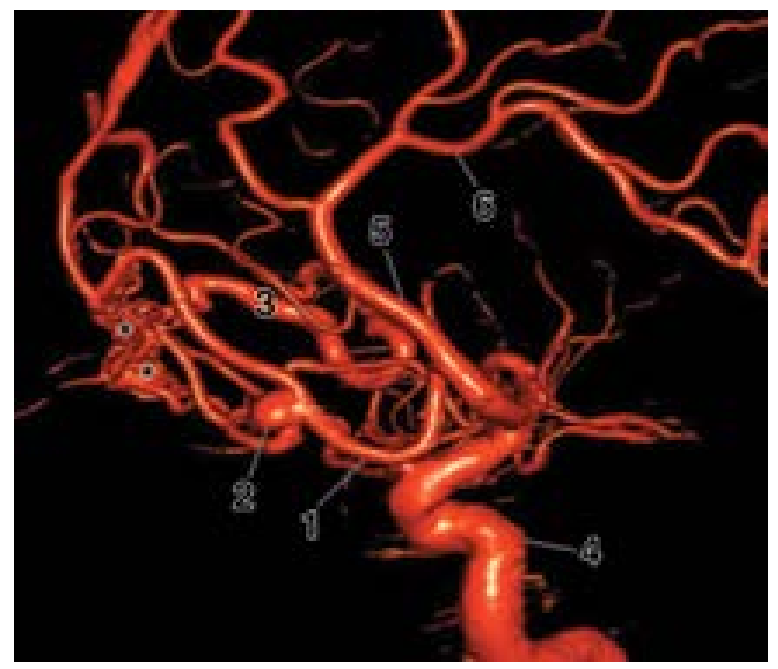

Figure 2. One source and one primary feeder of an arteriovenous malformation (asterisks) on the ventromedial surface of the superior frontal gyrus, which is fed by branches of the frontopolar artery (1). Note an aneurysm (2) of the latter artery at its branching site, as well as a draining vein (3). 4 - the internal carotid artery; 5 - the A2 segment of the right anterior cerebral artery; 6 - the pericallosal artery. Lateral and slightly oblique carotid three-dimensional angiogram.

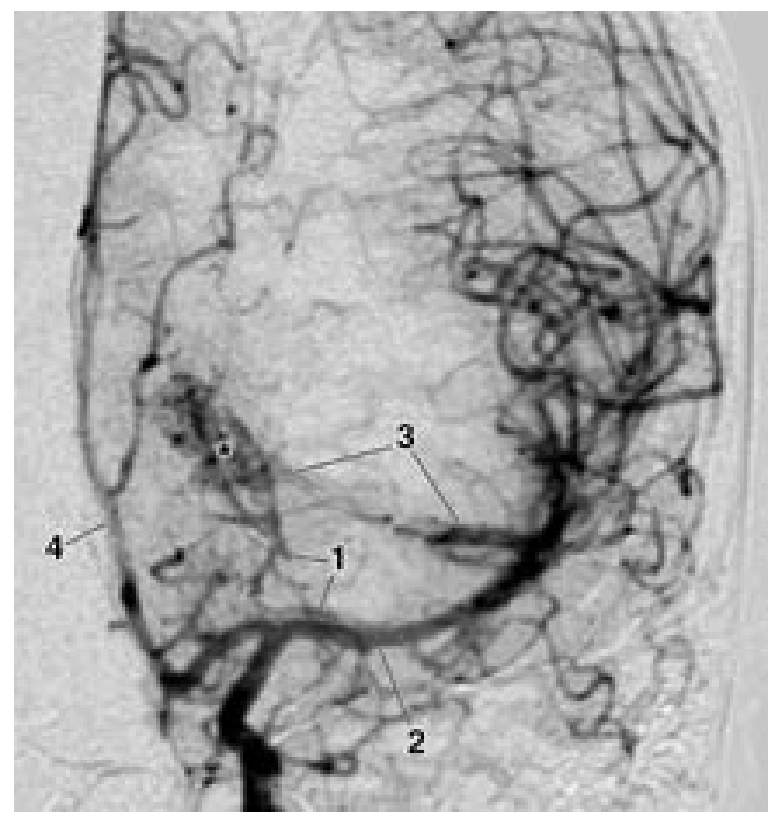

Figure 3. A small arteriovenous malformation (asterisk) in the head of the caudate nucleus is supplied by a lenticulostriate branch (1) of the M1 segment (2) of the left middle cerebral artery. Note a postnidal vein (3), which drains into the sphenoparietal sinus, and the A2 segment (4) of the left anterior cerebral artery. The anteroposterior carotid angiogram.

respectively, within the supratentorial compartment (Fig. 8). Several feeders can be observed in the infratentorial compartment as well, e.g. the SCA, AICA and PICA (Fig. 9). Multiple feeders belonged to the

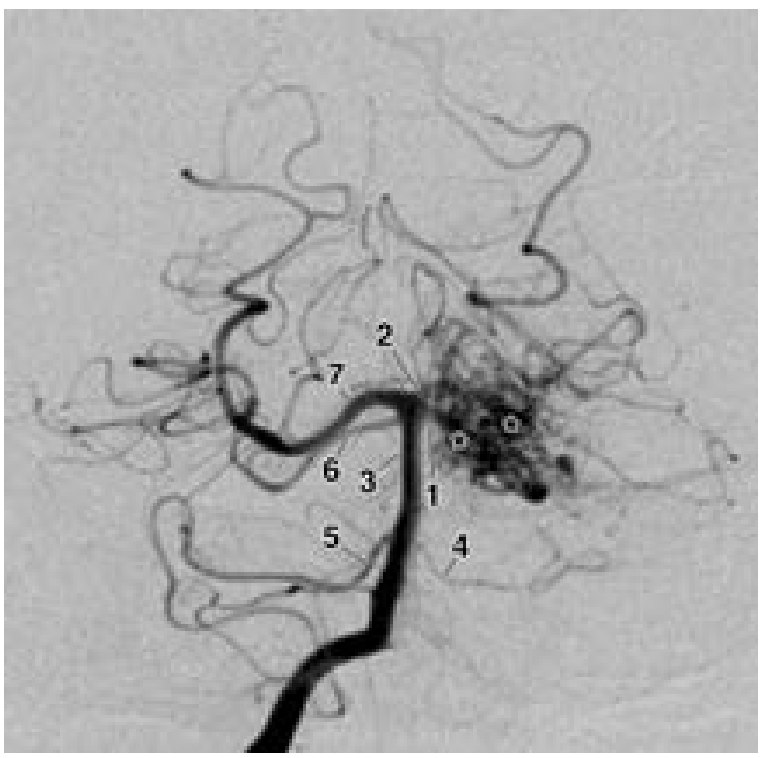

Figure 4. One source within the infratentorial compartment, i.e. in the posterior cranial fossa. An arteriovenous malformation (asterisks), which is mainly located on the superolateral part of the pons, is fed by a large left superior cerebellar artery (1). 2 - the left posterior cerebral artery; 3 - the basilar artery; 4 and 5 - the left and right anterior inferior cerebellar arteries; 6 - the right superior cerebellar artery; 7 - the right posterior cerebral artery. The anteroposterior vertebral angiogram.

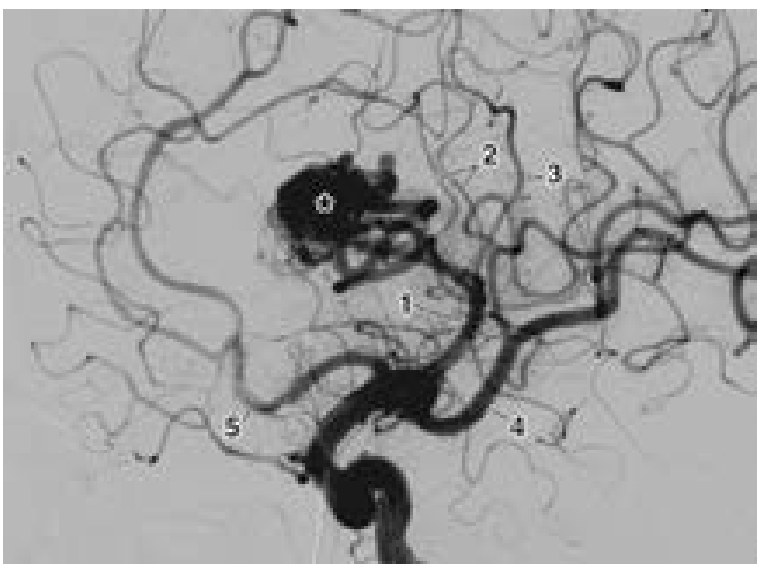

Figure 5. Two feeding vessels from the middle cerebral artery. A lateral and slightly oblique view of an arteriovenous malformation (asterisk) in the fronto-opercular region, which is supplied by two prefrontal arteries arising from the superior (or anterior) terminal trunk (1) of the left middle cerebral artery. 2 - the precentral arteries; 3 - the central artery; 4 - the inferior terminal trunk; 5 - the A2 segment of the anterior cerebral artery.

leptomeningeal vessels, but some of them were of the perforating or the choroidal type (Fig. 10).

Regardless of their number (except in the case with a singular vessel), the feeders may arise, as already mentioned, from the same parent artery or from different arteries (Table 1). In the former cases, 


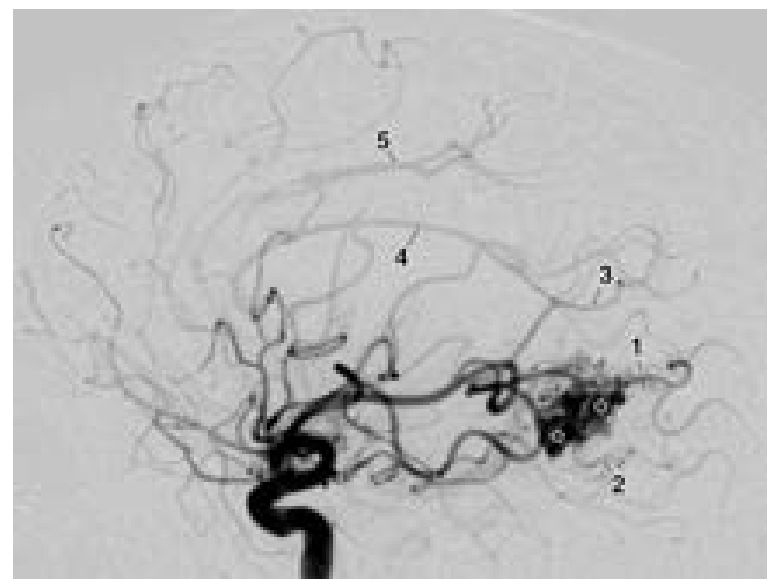

Figure 6. Another two feeding vessels from the middle cerebral artery. An arteriovenous malformation (AVM) (asterisks) is mainly located on the posterior part of the left superior temporal and middle temporal gyri. Its feeding vessels comprise the angular gyrus artery (1) and the temporo-occipital artery (2). Note the superior parietal branch (3) of the middle cerebral artery, and the pericallosal (4) and callosomarginal artery (5) of the anterior cerebral artery. The AVM contains several small intranidal aneurysms. The lateral carotid angiogram.

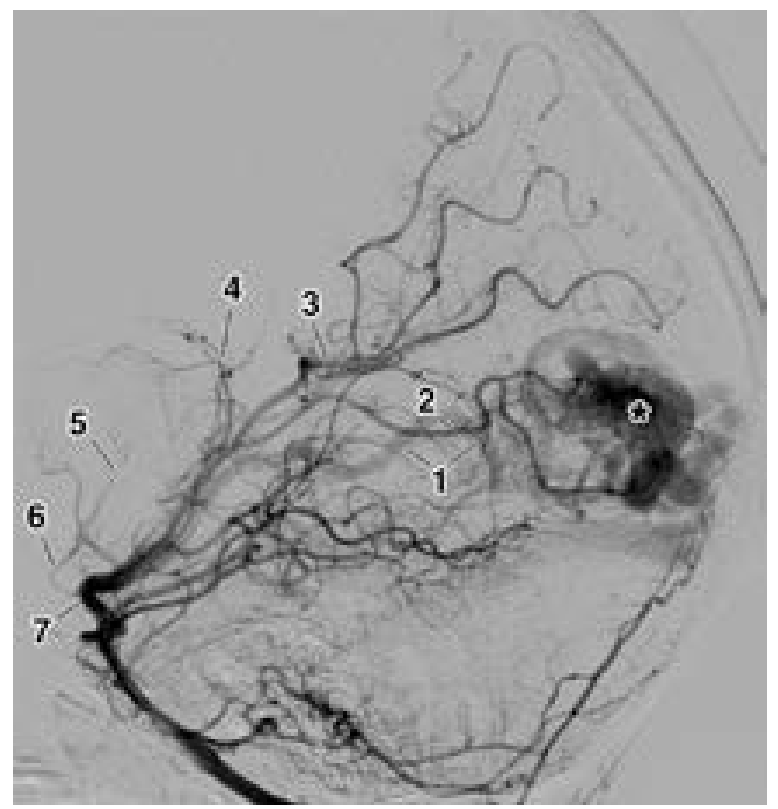

Figure 7. A corticosubcortical anterior cerebral artery (AVM) (asterisk) which is mainly located in the posterior part of the lateral and medial occipitotemporal gyri. This AVM is predominantly fed by a large posterior temporal branch (1) of the posterior cerebral artery, and only slightly by the calcarine artery (2). Note the parieto-occipital artery (3), the lateral and medial posterior choroidal arteries (4), the mesencephalic perforators (5), the thalamoperforating arteries (6), and the left posterior cerebral artery (7). The lateral vertebral angiogram.

the feeders most often originated from the MCA (23.38\%), less frequently from the ACA $(12.99 \%)$ and the PCA $(10.39 \%)$, and rarely from the ICA or

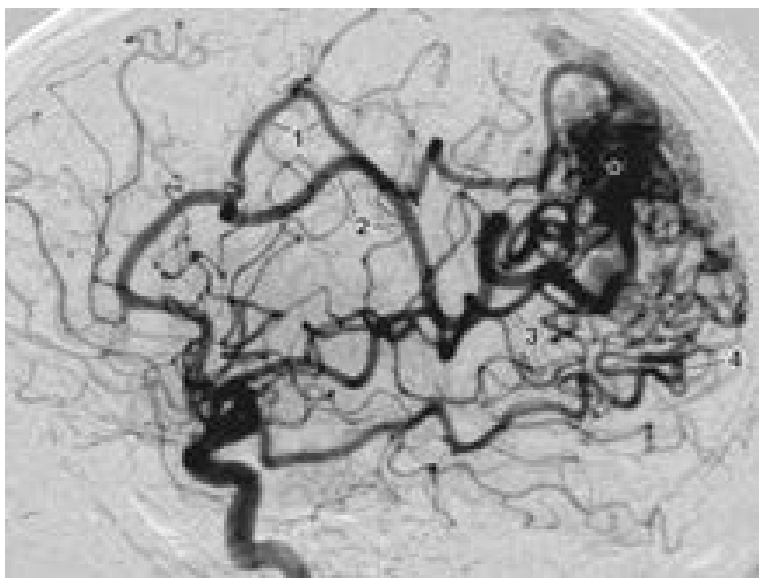

Figure 8. Three sources and four primary feeders of an anterior cerebral artery (asterisk) within the supratentorial compartment, i.e. in the parieto-occipital region. Note the callosomarginal (1) and the pericallosal artery (2) of the anterior cerebral artery, the posterior parietal artery (3) of the middle cerebral artery, and the parieto-occipital artery (4) of the posterior cerebral artery, the latter presenting a carotid origin. The lateral carotid angiogram.

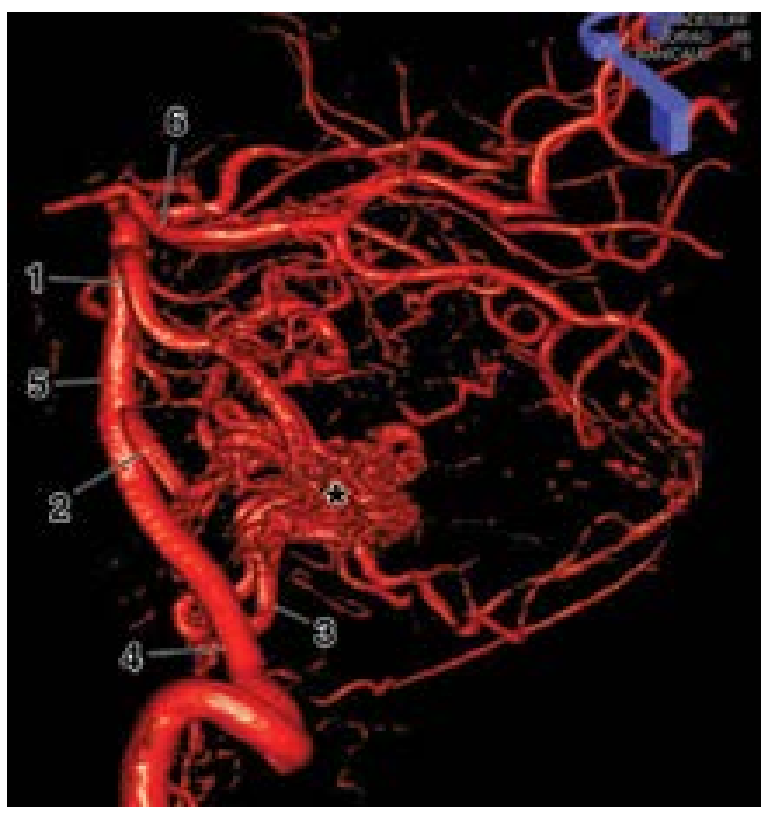

Figure 9. Three feeders in the infratentorial compartment. An anterior cerebral artery (asterisk) receives blood from the left superior cerebellar artery (1), the anterior inferior cerebellar artery (2), and the posterior inferior cerebellar artery (3). Note the vertebral artery (4), the basilar artery (5), and the left posterior cerebral artery (6). The lateral vertebral three-dimensional angiogram.

the cerebellar arteries (Table 1). The feeders of some AVMs arose from two different parent arteries, most often from the ACA and MCA (11.69\%), as well as from the MCA and PCA (10.39\%), and ACA and PCA (7.79\%) (Table 1). In 1 patient the AVM was supplied by both ACAs, i.e. by the pericallosal and calloso- 


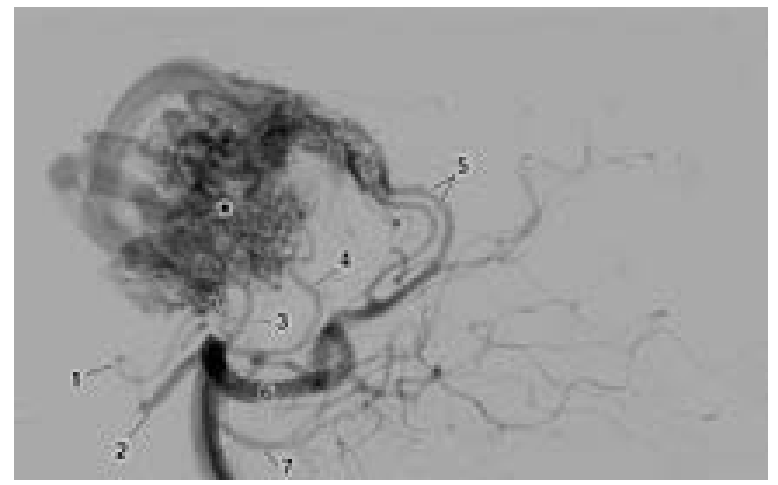

Figure 10. Four feeders from the same parent artery (posterior cerebral artery), and one from the posterior communicating artery. A large anterior cerebral artery (AVM) (asterisk) occupies the anterior part and the adjacent superolateral portion of the thalamus. The AVM is supplied by the premammillary perforator (1) from the posterior communicating artery (2), and by the thalamogeniculate branch (3), the medial posterior choroidal artery (4), and two lateral posterior choroidal arteries (5) from the posterior cerebral artery (6). Note the superior cerebellar artery (7). The lateral and slightly oblique vertebral angiogram.

marginal arteries on the ipsilateral side, and by the callosomarginal artery on the opposite side. Finally, multiple feeders were noticed to originate from three or four parent arteries, most often from the ACA, MCA and PCA (Fig. 8, Table 1). In 3 of these patients, there was also a contribution of the ECA (Table 1), i.e. of the middle meningeal and occipital arteries.

The primary feeders (Table 2 ) were identified as the following: the primitive trigeminal artery of the ICA; the pericallosal, callosomarginal, frontopolar, and posterior internal frontal branches of the ACA; the prefrontal, central, anterior and posterior parietal, angular gyrus, temporo-occipital, and perforating (lenticulostriate) branches of the MCA; the choroidal twigs of the AChA; the premammillary branch of the PComA; the parieto-occipital, calcarine, collicular, posterior temporal, and the perforating branches of the PCA, including the choroidal vessels (the MPChA and LPChA); and, the small twigs of the SCA, AICA and PICA. Most of the feeders belonged to the leptomeningeal branches, and others to the perforating or the choroidal vessels. There were also certain combinations of these types of the feeders of some AVMs (Fig. 10).

\section{The appearance of feeding arteries}

The feeders in the majority of the AVMs (58.44\%) were dilated and elongated, often showing a tortuous course (Figs. 5-8). Although the vessel diameters were not measured directly, it was obvious that the lumen of some of them was much larger than that of the
Table 1. Origin of the feeding vessels

\begin{tabular}{lc}
\hline Parent arteries & Frequency \\
\hline ICA & $1.30 \%$ \\
ACA & $12.99 \%$ \\
MCA & $23.38 \%$ \\
PCA & $10.39 \%$ \\
SCA & $2.60 \%$ \\
AICA & $1.30 \%$ \\
ACA-ACA & $1.30 \%$ \\
ACA-MCA & $11.69 \%$ \\
ACA-PCA & $7.79 \%$ \\
MCA-PCA & $10.39 \%$ \\
AChA-PCA & $1.30 \%$ \\
PComA-PCA & $1.30 \%$ \\
SCA-AICA & $3.89 \%$ \\
ACA-MCA-PCA & $5.19 \%$ \\
SCA-AICA-PICA & $1.30 \%$ \\
MCA-PCA-ECA & $2.60 \%$ \\
ACA-MCA-PCA-ECA & $1.30 \%$ \\
\hline
\end{tabular}

ACA — anterior cerebral artery; AChA — anterior choroidal artery; AICA — anterior inferior cerebellar artery; ICA — internal carotid artery; ECA — external carotid artery; MCA — middle cerebral artery; LPChA lateral posterior choroidal arteries; MPChA medial posterior choroidal arteries; PCA — posterior cerebral artery; PComA — posterior communicating artery; PICA — posterior inferior cerebellar artery; SCA — superior cerebellar artery

Table 2. Feeding arteries of the supratentorial arteriovenous malformations (AVMs)

\begin{tabular}{lc}
\hline Source & Type of arteries \\
\hline ICA & Primitive trigeminal \\
ACA & Pericallosal \\
& Callosomarginal \\
& Frontopolar \\
& Posterior internal frontal \\
MCA & Prefrontal \\
& Central \\
& Anterior parietal \\
& Posterior parietal \\
& Angular gyrus \\
& Temporo-occipital \\
AChA & Lenticulostriate \\
PComA & Choroidal \\
PCA & Premammillary \\
& Parieto-occipital \\
& Calcarine \\
& Posterior temporal \\
& Collicular \\
& Thalamoperforating \\
& Thalamogeniculate \\
& Medial posterior choroidal \\
& Lateral posterior choroidal \\
\hline
\end{tabular}

Abbreviations - see Table 1 
similar adjacent arteries, or of the same vessels of the opposite hemisphere. The enlargement and tortuosity were especially expressed in the cases of multiple leptomeningeal feeders, arising either from a single or several parent arteries, and in large-sized AVMs (Fig. 8).

Finally, in 2 patients we observed an aneurysm on the feeding arteries. One was located at the branching site of a feeder (Fig. 2), and another one on the supraclinoid segment of the ICA. In addition, intranidal (Fig. 6) and postnidal venous pouches or aneurysms were noticed in 9 patients. Some of them were more than $3 \mathrm{~cm}$ in diameter. Aneurysms are one of the causes of an intracranial haemorrhage, which was observed in $63.6 \%$ of the AVMs in our patients.

\section{DISCUSSION}

We shall first shortly consider the vascular anatomic data, and then the AVMs pathogenesis, the anatomic features of the feeding arteries and their parent vessels, and finally their clinical significance.

\section{Anatomic aspect}

Dissected specimens in our study helped to identify each feeding artery in the carotid and vertebral angiograms of our patients, i.e. the corresponding leptomeningeal, perforating and choroidal branches. All the identified vessels were checked in the corresponding publications $[6,7,12,15-17,20,22,25,37,38,57$, $64,66,67,72,76]$. The results of our anatomic study were in accordance with data in the latter reports.

As regards the anatomic variations of the arteries, a few of them were observed in our specimens. They were related to a sporadic hypoplasia of some vessels (the $\mathrm{A} 1$ segment and the $\mathrm{P} 1$ segment, as well as the VA) in 1 case each, their "hyperplasia" (the PComA) in 1 case, early bifurcation (the M1 segment, and the SCA) in one specimen each, and a single duplication (the SCA).

\section{The AVMs pathogenesis}

The AVMs consist of a group of abnormal tortuous vessels (the nidus), the vascular core of which occurs during the embryonic development in most cases $[16,43,53,55,78]$. The majority of the arteries within the AVMs undergo normal maturation in the prenatal and postnatal period, but the veins retain some of their embryonic features. The capillary network in the nidus is either absent or contains some dilated microvessels $[16,53,55]$.

Due to the shunt of blood from the arteries directly to the veins in many AVMs, a high blood flow appears, which causes, among others, structural changes in the vessel wall, and venous hypertension in the nidus and the draining veins $[4,16,24,39,43,53,55,58]$. This high venous pressure may lead to hypoperfusion with resultant hypoxia or ischaemia in the local brain parenchyma with consequent focal neurologic deficits or epileptic focus formation $[9,29,62,80]$. At the same time, hypoxia and ischemia within the nidus itself initiate an inflammatory response with production of cytokines, which cause endothelium disorder and activation of the angiogenic factors $[47,53]$. The resulting intranidal angiogenesis, along with the mentioned higher intranidal and postnidal venous pressure, gradually remodel the AVMs vascular network.

Although AVMs incidence is very low in the general population (0.02-0.05\%) [32], they account for up to $2 \%$ of all haemorrhagic strokes, thus markedly contributing to the morbidity and mortality rate of cerebrovascular disorders $[8,53,58,78,80]$. Because of that, any type of research in the AVMs field is very important in understanding their structure, pathophysiology, natural course, the angiographic appearance, and neurologic consequences, as well as in decisions regarding their therapy.

\section{Anatomy of feeding arteries}

As regards the identification of these vessels in carotid and vertebral angiograms, our anatomic study was of a great help, but also our previous experience in the brain vasculature, as well as the angiographic data reported by certain authors $[7,16,46,64,68,78]$.

As already mentioned, from 1 to 6 feeders were seen to supply the corresponding AVMs in our study. We counted, however, only the primary feeders, and not their branches which entered the AVM. For example, the frontopolar artery in Figure 3 divides into two main branches which reached the AVM, but it was classified as a singular feeding vessel.

The AVMs appeared more often in the supratentorial compartment $(90.9 \%)$, and less frequently in the infratentorial region $(9.1 \%)$ of our patients (Table 1 ). The latter frequency $(9.1 \%)$ is within the range of $2-15 \%$ reported by other authors $[5,16,24,78]$. The parent vessel of the feeders was most often the MCA in our patients, followed by the ACA and PCA, and less frequently the ICA, AChA, PComA, BA and VA. Similar results were reported by other authors $[16,78]$.

Obviously, the AVMs can be located in any part of the brain, which means that any cerebral artery can become a feeder $[1,5,14,16,18,24,27,33$, 
$34,45,46,50,51,61,65,74,78]$. The type of the feeding vessels depends firstly on a deep or superficial AVMs position.

In the former case, the AVMs are mainly supplied by the perforating vessels or the choroidal arteries (Figs. 3, 10). These deep AVMs were rare in our patients, as were in other reports which mentioned a frequency of up to $18 \%[14,24$, $35,70,73]$. As regards the type of the perforators, the latter authors identified the lenticulostriate arteries of the MCA, as well as the TPA of the PCA, the perforators of the $B A$, and very rarely the premammillary twig of the PComA (Fig. 10). However, the thalamogeniculate vessels (Fig. 10) have never been mentioned in literature as the AVMs feeders. Nevertheless, these deep AVMs, either striatal, thalamic, or those within the brain stem, are most often manifested by focal neurologic deficits or as an intracerebral or intraventricular haemorrhage.

Some perforating feeders could be damaged during surgery of such AVMs $[14,45]$. These feeders, especially the lenticulostriate arteries and the perforators of the brain stem, must be preserved during the intervention. Most often an endovascular treatment or stereotactic radiosurgery are performed in these patients, and less frequently a neurosurgical intervention $[14,45,70,75,79]$. However, if radiologic embolisation of a perforating feeder could cause serious local ischaemia, especially in the adjacent internal capsule, in the thalamus, or within the important brain stem structures, a microsurgical resection of such an AVM is recommended [46].

The intraventricular, i.e. the thalamic AVMs in our 3 patients, received blood from the premammillary, collicular, thalamoperforating, or thalamogeniculate twigs, as well as from the corresponding choroidal arteries, that is, the AChA, MPChA or LPChA (Fig. 10). As for the TPA, one of them was reported to supply a thalamic AVM from the opposite side [46]. Such a perforator, which perfused both the right and left thalamus, was observed in one of our anatomic specimens. The other feeders mentioned in our patients were noticed by certain authors as well $[18,26,42$, $61,70]$, except the thalamogeniculate vessel and the collicular artery. As regards the PICA's choroidal twigs, they are very rarely the feeders of the AVMs in the region of the fourth ventricle $[65,74]$. Nevertheless, in patients with thalamic and intraventricular AVMs, the radiologic endovascular treatment is usually applied $[18,26,51]$.
In the cases of superficial AVMs, which occur more frequently than deeper ones, the leptomeningeal (pial) vessels are most often engaged as the feeders. As regards the ICA, a primitive trigeminal artery was noticed in one of our patients, which supplied a small perimesencephalic AVM. It was also rarely observed by other authors to feed the cerebral AVMs of different locations [1, 44, 48]. The primitive trigeminal artery may belong to various types. Namely, it may connect the cavernous segment of the ICA with the distal part of the $B A$, or may represent a cerebellar artery (the SCA, AICA or PICA) arising from the ICA instead of from the BA or the VA $[1,37,48]$. The feeders originating from some other persistent embryonal vessels were seen extremely rarely, e.g. from the primitive olfactory or hypoglossal artery $[28,50]$. Finally, some AVMs feeders are associated with the arterial fenestration [71], and some others with the moyamoya vessels $[3,49]$.

In our patients with the superficial AVMs, various leptomeningeal branches were seen to be their feeders. They commonly originated from the MCA, and less frequently from the ACA, PCA, BA or VA (Tables 1, 2). In general, our results are in accordance with other reports $[16,24,34,50,56,61,78]$. Nevertheless, it is obvious that the AVMs location and the position of the parent arteries mainly determine the type of the feeders.

As regards the ACA in our patients, the medial orbitofrontal artery was not a feeder, nor the paracentral, superior parietal, precuneal, and some internal frontal arteries. In other reports, most often the pericallosal, callosomarginal and frontopolar arteries of the ACA were mentioned as the feeders, but not the internal frontal, paracentral, and the superior parietal arteries $[16,68,78]$. As regards the subcallosal branch of the AComA, it was never seen to supply AVMs $[16,78]$.

In the MCA territory, the angular gyrus artery was most often involved in our patients. The same feeder was mentioned by certain authors $[16,61$, 78], while the parietal vessels were reported by some others [73]. On the other hand, the precentral and temporal arteries were not observed as the feeders in our patients, except the temporo-occipital artery. Certain authors revealed some of them as the AVMs supplying vessels, e.g. the anterior, middle, and posterior temporal arteries [18].

The AChA contributed to a thalamic AVM supply in only one of our patients. Other authors also noticed this artery to perfuse some thalamic AVMsl, as well as the choroidal and medial temporal ones $[26,42,78]$. 
In case of the AVMs in the PCA territory, the anterior and middle temporal arteries, as well as the uncal, hippocampal and parahippocampal vessels, were not the feeders in our patients. The AVMs was most often supplied by the parieto-occipital artery, and rarely by the calcarine and posterior temporal vessels, as well as by the corresponding choroidal arteries, i.e. the MPChA and the LPChA. The calcarine feeder was infrequently mentioned in literature [33].

As regards the PComA, a contribution of its premammillary branch, found in one of our patients, was very rarely reported by other authors $[51,61]$.

In the VA region, the perforating, anterolateral and lateral medullary arteries, as well as the anterior spinal artery, did not supply the AVMs in our patients, but only the PICA in one case with multiple feeders (Fig. 9). Some of the mentioned vessels were noticed as the sporadic feeders in certain reports $[24,27]$.

As regards the $B A$, we found the cerebellar arteries, i.e. the AICA and the SCA, to feed the AVMs, but not the perforating, the anterolateral, inferolateral, superolateral, and posterolateral pontine twigs [15]. Certain authors, however, identified some of these vessels as supplying the AVMs of the brain stem in rare cases [24].

Finally, we observed some ECA branches in 3 patients (Table 1) to contribute to the leptomeningeal AVMs supply, that is, the middle meningeal and the occipital artery, respectively. Other authors found sporadically the same arteries as the accessory AVMs feeders $[16,41]$, and very rarely some of the persistent primitive arteries in the dural region [28]. Some authors registered dural vascular connections with intraventricular AVMs [74]. According to certain reports, some contribution of dural arteries is present in more than $20 \%$ of patients, especially in those with large superficial AVMs [31, 41].

There is a partial explanation of these events from the anatomic aspect [11, 21]. Namely, some cerebral arteries normally give rise to certain meningeal branches, e.g. the ICA (tentorial branch of the meningohypophyseal trunk, and smaller branches from the ophthalmic artery), the BA (some small dural twigs), and the VA (the posterior meningeal artery). Secondly, there are dural ECA branches as well, e.g. the middle meningeal artery of the maxillary artery, and small dural twigs of the occipital and the ascending pharyngeal arteries. Some of these twigs form the anastomotic channels among them in the dural region where, in addition, sporadic pre-existing small arteriovenous shunts are usually present. Such vascular connections may develop into some larger anastomotic and arteriovenous channels which can form dural AVMs or dural arteriovenous fistulas [11, $16,78]$. In some way, certain dural vessels can become the accessory feeders of some leptomeningeal AVMs, or of combined dural and pial AVMs.

\section{Clinical significance of the feeding arteries}

Microcatheterisation of the feeders and their parent arteries is a standard radiologic route to access the AVMs and to perform their endovascular embolisation $[4,16,50-52,68,80]$. It is understandable that great care must be taken to avoid damage to the feeders during such a procedure. Feeders' anatomy is important for microsurgical strategy as well $[4,14,18$, $24,27,45,69,75,78,80]$. In some cases, certain leptomeningeal feeding arteries, especially those of the brainstem AVMs, can be surgically occluded with no neurologic consequences $[24,27]$. The crucial thing is to perform occlusion close to the AVM, i.e. distal to the intraparenchymal side branches of the feeders. As regards the perforating feeders, these important vessels must be spared during the intervention [45].

High blood flow velocity and the flow volume rate in feeding arteries $[4,39,43,55,58]$ can cause certain structural changes in the vessel wall, that is, high-flow angiopathy $[8,16,55]$. It may consist of splitting or destruction of the internal elastic lamina, disorder of the smooth muscle layer (hyperplasia, fibrosis of the media coat, or focal disappearance of the smooth muscle cells), as well as endothelial cells proliferation.

Some of these changes usually result in an enlargement and tortuosity of the feeding arteries, as seen in many of our patients, and as reported by others $[16,68,78]$. Such feeders may occasionally compress certain neural structures and thus cause a neurologic manifestation, e.g. trigeminal neuralgia [34]. The mentioned endothelial proliferation and media coat changes can sometimes produce arterial stenosis which, along with an additional process of thrombosis or wall dissection, may progress to a complete occlusion of a feeder [16, 23].

The mentioned high blood flow through the feeders, along with decrease in or loss of vascular autoregulation, can result in a cerebral steal phenomenon. The latter is manifested by a hypoperfusion of the adjacent or distant regions of the brain with consecutive neurologic deficits $[9,16,30,59,78]$. However, this mechanism has been debated for several decades without a definite conclusion $[16,40]$. 
The mentioned haemodynamic processes in the AVMs may have another consequence, that is, a certain endothelial disorder, activation of the coagulation cascade and thrombosis of a feeding artery $[3,23,55]$. An embolism of the feeders or their parent arteries can occur as well, usually from the cardiac, carotid, or aneurysmal sources. In this situation, two consequences are possible. Firstly, a focal neurologic deficit occurrence and, secondly, a spontaneous AVM obliteration due to the intranidal stop of blood in some cases [32]. In the former instance, a mechanical endovascular thrombectomy of the parent artery could be performed [2]. In the latter situation the patient is practically free from the AVM. Unfortunately, such a spontaneous AVMs obliteration occurs in only $1-3 \%$ of patients [32].

In addition, a high blood flow within the feeders, including a turbulence appearance and share stress (i.e. the force which the blood exerts on the vessel wall), can damage the vessel wall and thus cause an aneurysm occurrence $[1,4,8,10,16,19,54,56,77]$. This is why the AVMs are relatively often associated with cerebral aneurysms, either prenidal arterial, or intranidal and postnidal venous aneurysms [10]. The prenidal aneurysms, which belong to the saccular type, are most often located on the feeding arteries, and occasionally on their parent vessels. We noticed two such aneurysms (2.6\%), one of which was situated at the branching site of the frontopolar artery (Fig. 2). Certain radiologists mentioned the aneurysms frequency of $2.7-23.0 \%$ in patients with the AVMs $[10,16]$.

The presence of an aneurysm on a feeding artery is very important clinically because it may rupture, either spontaneously, or during or after an endovascular radiologic procedure. In both cases, a dangerous subarachnoid haemorrhage occurs or an intraparenchymal haematoma develops [10, 50, 54, 78]. As regards the intranidal and postnidal venous pouches and aneurysms, they are out of the scope of this study.

As already mentioned, the AVMs vasculature has a certain risk of haemorrhage, which ranges between $0.9 \%$ to $34.3 \%$ of all the AVMs $[8,16,36,52,58,78]$. The risk is higher in the AVMs with a single feeding artery or with a single draining vein, in those with combined deep and superficial drainage, or with an infratentorial location, as well as in small-sized AVMs with high blood pressure within the feeders, and in the AVMs with coexisting aneurysms [36]. On the other hand, the nonhaemorrhagic AVMs are usually deeply located, with only perforating feeders, or with more than three leptomeningeal feeders or three draining veins [35].

In the cases of superficial (pial) AVMs bleeding, the resulting subarachnoid haemorrhage causes occasionally a vasospasm of the feeders $[13,78]$. A spasm may result in ischaemia of the brain parenchyma and the appearance of certain neurologic symptoms and signs. On the other hand, the spasm reduces the AVMs flow, which can induce a spontaneous thrombosis of the nidal vessels or draining veins in some patients [32].

According to certain post-mortem investigations, only $12 \%$ of the AVMs become symptomatic during life [16]. As regards the clinical manifestations, a focal motor or sensory deficit may occur, as well as dizziness, visual or speech disorders, or epileptic seizures $[9,16,23,24,29,33,35,36,62,80]$. Headaches are one of the most frequent symptoms. Most often, however, among the first signs of an AVM presence is intracranial bleeding, either in the form of intracerebral hematoma, or subarachnoid or intraventricular haemorrhage $[8,16,36,52,58,78]$. In our group, haemorrhage was the first sign of an AVM in $63.6 \%$ of patients, which is within a range of $30-82 \%$ reported by other authors [16].

The AVMs diagnosis is commonly made by a CT or magnetic resonance imaging (MRI) examination, but the most precise data can be obtained by performing a standard digital subtraction angiography $[7,16,68]$. In addition, 3D angiography is also used occasionally, as well as its combination with MRI scans, that is, the image fusion method $[60,62,63]$.

Finally, there are three main therapeutic techniques in the AVMs patients: a direct microsurgical resection, endovascular radiologic embolisation, and stereotactic radiosurgery, including their combinations sporadically $[16,24,52,60,68-70,78,79]$. In our patients, each of these techniques was used, either as a single method or in combination with other interventions. According to our study and the mentioned reports, deep AVMs should be predominantly treated by endovascular embolisation or radiosurgery, whilst the leptomeningeal ones by embolisation and, when necessary, by surgery. According to some authors, the success of such treatments is about $92 \%$ [80]. Our patients showed a similar outcome (89.6\%).

\section{CONCLUSIONS}

Arteriovenous malformations are very important disorders in human cerebrovascular pathology. They 
are fed by various branches of the main cerebral arteries, that is, the perforating, choroidal or, most often, leptomeningeal. One or more of the feeders most frequently arise from the middle, anterior, and posterior cerebral arteries, and rarely from the infratentorial vessels. Knowledge of the anatomic features of the feeding arteries is very important in diagnostics, therapy and prognosis of AVMs.

\section{REFERENCES}

1. Abe T, Matsumoto $K$, Aruga T. Primitive trigeminal artery variant associated with intracranial ruptured aneurysm and cerebral arteriovenous malformation--case report. Neurol Med Chir (Tokyo). 1994; 34(2): 104-107, indexed in Pubmed: 7514756.

2. Abla AA, Dumont TM, Kan P, et al. Stroke intervention for middle cerebral artery thrombus in a young patient with an ipsilateral Spetzler-Martin grade $V$ arteriovenous malformation. J Neurointerv Surg. 2013; 5(2): e10, doi: 10.1136/neurintsurg-2011-010164, indexed in Pubmed: 22345144.

3. Ahn SH, Choo InS, Kim JHo, et al. Arteriovenous malformation with an occlusive feeding artery coexisting with unilateral moyamoya disease. J Clin Neurol. 2010; 6(4): 216-220, doi: 10.3988/jcn.2010.6.4.216, indexed in Pubmed: 21264203.

4. Alaraj A, Shakur SF, Amin-Hanjani S, et al. Changes in wall shear stress of cerebral arteriovenous malformation feeder arteries after embolization and surgery. Stroke. 2015; 46(5): 1216-1220, doi: 10.1161/STROKEAHA.115.008836, indexed in Pubmed: 25813197.

5. Arnaout OM, Gross BA, Eddleman CS, et al. Posterior fossa arteriovenous malformations. Neurosurg Focus. 2009; 26(5): E12, doi: 10.3171/2009.2.FOCUS0914, indexed in Pubmed: 19408990.

6. Baptista AG. Studies on the arteries of the brain. li. The anterior cerebral artery: some anatomic features and their clinical implications. Neurology. 1963; 13: 825-835, indexed in Pubmed: 14066997.

7. Bradac GB, Boccardi E. Cerebral angiography. Normal anatomy and vascular pathology. Springer, London 2011: 1-314.

8. Rutledge WC, Ko NU, Lawton MT, et al. Hemorrhage rates and risk factors in the natural history course of brain arteriovenous malformations. Transl Stroke Res. 2014; 5(5): 538-542, doi: 10.1007/s12975-014-0351-0, indexed in Pubmed: 24930128

9. Choi JH, Mast H, Hartmann A, et al. Clinical and morphological determinants of focal neurological deficits in patients with unruptured brain arteriovenous malformation. J Neurol Sci. 2009; 287(1-2): 126-130, doi: 10.1016/j. jns.2009.08.011, indexed in Pubmed: 19729171.

10. D'Aliberti G, Talamonti G, Cenzato M, et al. Arterial and venous aneurysms associated with arteriovenous malformations. World Neurosurg. 2015; 83(2): 188-196, doi: 10.1016/j.wneu.2014.05.037, indexed in Pubmed: 24915068.

11. Davidson AS, Morgan MK. The embryologic basis for the anatomy of the cerebral vasculature related to arteriovenous malformations. J Clin Neurosci. 2011; 18(4):
464-469, doi: 10.1016/j.jocn.2010.12.004, indexed in Pubmed: 21330138.

12. Djulejić V, Marinković $S$, Milić $V$, et al. Common features of the cerebral perforating arteries and their clinical significance. Acta Neurochir (Wien). 2015; 157(5): 743-54; discussion 754, doi: 10.1007/s00701-015-2378-8, indexed in Pubmed: 25772345.

13. Doukas A, Petridis AK, Barth H, Jansen O, Maslehaty H, Mehdorn HM. Resistant vasospasmin subarachnoid hemorrhage treated with continuous intraarterial nimodipine infusion. In: Trends in neurovascular surgery. Springer, Wien 2011: 93-96.

14. Du R, Keyoung HM, Dowd CF, et al. The effects of diffuseness and deep perforating artery supply on outcomes after microsurgical resection of brain arteriovenous malformations. Neurosurgery. 2007; 60(4): 638-46; discussion 646, doi: 10.1227/01.NEU.0000255401.46151.8A, indexed in Pubmed: 17415200.

15. Duvernoy HM. Human brainstem vessels. In: Arteries and veins of the brainstem. Springer, Berlin Heidelberg 1978: 5-25.

16. Forsting $M$, Wanke I. Intracranial vascular malformations and aneurysms. From diagnostic work-up to endovascular therapy. 2nd Ed. Springer, Wien 2008: 1-295.

17. Fujii K, Lenkey C, Rhoton AL. Microsurgical anatomy of the choroidal arteries: lateral and third ventricles. J Neurosurg. 1980; 52(2): 165-188, doi: 10.3171/jns.1980.52.2.0165, indexed in Pubmed: 7351556.

18. Gabarrós Canals A, Rodríguez-Hernández A, Young WL, et al. UCSF Brain AVM Study Project. Temporal lobe arteriovenous malformations: anatomical subtypes, surgical strategy, and outcomes. J Neurosurg. 2013; 119(3): 616-628, doi: 10.3171/2013.6.JNS122333, indexed in Pubmed: 23848823.

19. Gao E, Young WL, Pile-Spellman J, et al. Cerebral arteriovenous malformation feeding artery aneurysms: a theoretical model of intravascular pressure changes after treatment. Neurosurgery. 1997; 41(6): 1345-56; discussion 1356, indexed in Pubmed: 9402586.

20. Gibo H, Carver CC, Rhoton AL, et al. Microsurgical anatomy of the middle cerebral artery. J Neurosurg. 1980; 54(2): 151-169, doi: 10.3171/jns.1981.54.2.0151, indexed in Pubmed: 7452329.

21. Gleeson M, Tunstall R. Head and neck: overview and surface anatomy. In: Gray's Anatomy. The anatomical basis of clinical practice. Elsevier, London 2016: 404-415.

22. Gomes FB, Dujovny M, Umansky F, et al. Microanatomy of the anterior cerebral artery. Surg Neurol. 1986; 26(2): 129-141, indexed in Pubmed: 3726739.

23. Goto H, Suzuki M, Akimura T, et al. Progression of stenosis into occlusion of the distal posterior cerebral artery supplying an occipital arteriovenous malformation manifesting as multiple ischemic attacks: case report. Neurol Med Chir (Tokyo). 2012; 52(12): 899-902, indexed in Pubmed: 23269045.

24. Han SJ, Englot DJ, Kim H, et al. Brainstem arteriovenous malformations: anatomical subtypes, assessment of "occlusion in situ" technique, and microsurgical results. J Neurosurg. 2015; 122(1): 107-117, doi: 10.3171/2014.8.JNS1483, indexed in Pubmed: 25343188.

25. Hupperts RM, Lodder J, Heuts-van Raak EP, et al. Infarcts in the anterior choroidal artery territory. Anatomical dis- 
tribution, clinical syndromes, presumed pathogenesis and early outcome. Brain. 1994; 117 (Pt 4): 825-834, indexed in Pubmed: 7922468.

26. Isozaki M, Satow T, Matsushige $T$, et al. Superselective provocative test with propofol using motor-evoked potential monitoring for managing cerebral arteriovenous malformations fed by the anterior choroidal artery. J Stroke Cerebrovasc Dis. 2016; 25(9): e153-e157, doi: 10.1016/j.jstrokecerebrovasdis.2016.05.034, indexed in Pubmed: 27318650.

27. Ito M, Yamamoto $T$, Mishina $H$, et al. Arteriovenous malformation of the medulla oblongata supplied by the anterior spinal artery in a child: treatment by microsurgical obliteration of the feeding artery. Pediatr Neurosurg. 2000; 33(6): 293-297, doi: 10.1159/000055974, indexed in Pubmed: 11182639.

28. Jimbo $H$, Ikeda $Y$, Izawa $H$, et al. Mixed pial-dural arteriovenous malformation in the anterior cranial fossa--two case reports. Neurol Med Chir (Tokyo). 2010; 50(6): 470-475, indexed in Pubmed: 20587971.

29. Josephson CB, Rosenow F, Al-Shahi Salman R. Intracranial vascular malformations and epilepsy. Semin Neurol. 2015; 35(3): 223-234, doi: 10.1055/s-0035-1552621, indexed in Pubmed: 26060902.

30. Kim DJ, Krings T. Whole-brain perfusion CT patterns of brain arteriovenous malformations: a pilot study in 18 patients. AJNR Am J Neuroradiol. 2011; 32(11): 2061-2066, doi: 10.3174/ajnr.A2659, indexed in Pubmed: 21885720.

31. Koo HW, Jo KI, Yeon JY, et al. Clinical features of superficially located brain arteriovenous malformations with transdural arterial communication. Cerebrovasc Dis. 2016; 41(3-4): 204-210, doi: 10.1159/000443530, indexed in Pubmed: 26789929.

32. Krapf H, Siekmann R, Freudenstein D, et al. Spontaneous occlusion of a cerebral arteriovenous malformation: angiography and MR imaging follow-up and review of the literature. AJNR Am J Neuroradiol. 2001; 22(8): 1556-1560, indexed in Pubmed: 11559505.

33. Kupersmith MJ, Vargas ME, Yashar A, et al. Occipital arteriovenous malformations: visual disturbances and presentation. Neurology. 1996; 46(4): 953-957, indexed in Pubmed: 8780071.

34. Li ZY, Liang JT, Zhang HQ, et al. Trigeminal neuralgia caused by a dilated superior cerebellar artery and a draining vein of cerebellar arteriovenous malformations: a case report and review of the literature. Acta Neurochir (Wien). 2017; 159(4): 689-694, doi: 10.1007/s00701-016-3061-4, indexed in Pubmed: 28124740.

35. Lv X, Li Y, Yang $X$, et al. Characteristics of brain arteriovenous malformations in patients presenting with nonhemorrhagic neurologic deficits. World Neurosurg. 2013; 79(3-4): 484-488, doi: 10.1016/j.wneu.2012.04.006, indexed in Pubmed: 22484767.

36. Lv X, Wu Z, Jiang C, et al. Angioarchitectural characteristics of brain arteriovenous malformations with and without hemorrhage. World Neurosurg. 2011; 76(1-2): 95-99, doi: 10.1016/j.wneu.2011.01.044, indexed in Pubmed: 21839959

37. Marinković S, Gibo H, Brigante L, Milisavljević M, Donzelli R. Arteries of the brain and spinal cord. Anatomic features and clinical significance. De Angelis, Avellino 1997: 1-264.
38. Marinković S, Gibo H, Milisavljević M. The surgical anatomy of the relationships between the perforating and the leptomeningeal arteries. Neurosurgery. 1996; 39(1): 72-83, indexed in Pubmed: 8805142.

39. Markl M, Wu C, Hurley MC, et al. Cerebral arteriovenous malformation: complex 3D hemodynamics and 3D blood flow alterations during staged embolization. J Magn Reson Imaging. 2013; 38(4): 946-950, doi: 10.1002/jmri.24261, indexed in Pubmed: 24027116.

40. Mast H, Mohr JP, Osipov A, et al. 'Steal' is an unestablished mechanism for the clinical presentation of cerebral arteriovenous malformations. Stroke. 1995; 26(7): 1215-1220, indexed in Pubmed: 7604417.

41. Miyachi S, Negoro M, Handa T, et al. Contribution of meningeal arteries to cerebral arteriovenous malformations. Neuroradiology. 1993; 35(3): 205-209, indexed in Pubmed: 8459921.

42. Miyasaka Y, Yada K, Ohwada T, et al. Choroid plexus arteriovenous malformations. Neurol Med Chir (Tokyo). 1992; 32(4): 201-206, indexed in Pubmed: 1378563.

43. Moftakhar P, Hauptman JS, Malkasian D, et al. Cerebral arteriovenous malformations. Part 2: physiology. Neurosurg Focus. 2009; 26(5): E11, doi: 10.3171/2009.2.FOCUS09317, indexed in Pubmed: 19408989.

44. Mohanty CB, Devi BI, Somanna S, et al. Corpus callosum arteriovenous malformation with persistent trigeminal artery. Br J Neurosurg. 2011; 25(6): 736-740, doi: 10.3109 /02688697.2011.554583, indexed in Pubmed: 21501055.

45. Morgan MK, Drummond KJ, Grinnell V, et al. Surgery for cerebral arteriovenous malformation: risks related to lenticulostriate arterial supply. J Neurosurg. 1997; 86(5): 801-805, doi: 10.3171/jns.1997.86.5.0801, indexed in Pubmed: 9126895.

46. Motegi $H$, Terasaka S, Shiraishi $H$, et al. Thalamic arteriovenous malformation fed by the artery of Percheron originating from the contralateral posterior cerebral artery in a child. Childs Nerv Syst. 2014; 30(7): 1313-1315, doi: 10.1007/s00381-013-2343-x, indexed in Pubmed: 24389663.

47. Mouchtouris N, Jabbour PM, Starke RM, et al. Biology of cerebral arteriovenous malformations with a focus on inflammation. J Cereb Blood Flow Metab. 2015; 35(2): 167-175, doi: 10.1038/jcbfm.2014.179, indexed in Pubmed: 25407267.

48. Nakai Y, Yasuda S, Hyodo A, et al. Infratentorial arteriovenous malformation associated with persistent primitive trigeminal artery: case report. Neurol Med Chir (Tokyo). 2000; 40(11): 572-574, indexed in Pubmed: 11109794.

49. Noh JH, Yeon JeY, Park JH, et al. Cerebral arteriovenous malformation associated with moyamoya disease. J Korean Neurosurg Soc. 2014; 56(4): 356-360, doi: 10.3340/ jkns.2014.56.4.356, indexed in Pubmed: 25371789.

50. Pavlisa G, Rados M, Ozretic D, et al. Endovascular treatment of AVM-associated aneurysm of anterior inferior cerebellar artery through persistent primitive hypoglossal artery. Br J Neurosurg. 2012; 26(1): 86-88, doi: 10.3109/ 02688697.2011.584983, indexed in Pubmed: 21707243.

51. Piotin M, Mounayer C, Spelle L, et al. Endovascular treatment of anterior choroidal artery aneurysms. AJNR Am J Neuroradiol. 2004; 25(2): 314-318, indexed in Pubmed: 14970038. 
52. Rahme R, Farley CW, Zuccarello M, et al. Transarterial embolization of cerebral arteriovenous malformations: a durable treatment for venous side hemorrhage? Med Hypotheses. 2011; 76(6): 827-830, doi: 10.1016/j. mehy.2011.02.029, indexed in Pubmed: 21421288.

53. Rangel-Castilla L, Russin JJ, Martinez-Del-Campo E, et al. Molecular and cellular biology of cerebral arteriovenous malformations: a review of current concepts and future trends in treatment. Neurosurg Focus. 2014; 37(3): E1, doi: 10.3171/2014.7.FOCUS14214, indexed in Pubmed: 25175428.

54. Reynolds MR, Arias EJ, Chatterjee AR, et al. Acute rupture of a feeding artery aneurysm after embolization of a brain arteriovenous malformation. Interv Neuroradiol. 2015; 21(5): 613-619, doi: 10.1177/1591019915591740, indexed in Pubmed: 26126431.

55. Rubin E, Reisner HM. Essentials of Rubin's pathology. 5th Ed. Lippincott Williams \& Wilkins, a Wolters Kluwer business 2009: 1-648.

56. Santucci N, Gazzeri G, Tamorri M. Association of two saccular aneurysms of the posterior inferior cerebellar artery with a cerebellar arteriovenous malformation fed by the same artery. Case report. J Neurosurg Sci. 1985; 29(2): 109-112, indexed in Pubmed: 4093797.

57. Schlesinger B. Extraparenchymal upper brainstem arteries. In: The upper brainstem in the human: its nuclear configuration and vascular supply. Springer, Berlin 1970: 75-175.

58. Shakur SF, Amin-Hanjani S, Mostafa H, et al. Relationship of pulsatility and resistance indices to cerebral arteriovenous malformation angioarchitectural features and hemorrhage. J Clin Neurosci. 2016; 33: 119-123, doi: 10.1016/j. jocn.2016.02.034, indexed in Pubmed: 27595365.

59. Sheth RD, Bodensteiner JB. Progressive neurologic impairment from an arteriovenous malformation vascular steal. Pediatr Neurol. 1995; 13(4): 352-354, indexed in Pubmed: 8771176.

60. Stancanello J, Cavedon C, Francescon P, et al. Development and validation of a CT-3D rotational angiography registration method for AVM radiosurgery. Med Phys. 2004; 31(6): 1363-1371, doi: 10.1118/1.1751252, indexed in Pubmed: 15259640

61. Sugita K, Takemae T, Kobayashi S. Sylvian fissure arteriovenous malformations. Neurosurgery. 1987; 21(1): 7-14, indexed in Pubmed: 3614608.

62. Sun Y, Tian RF, Li AM, et al. Unruptured Epileptogenic Brain Arteriovenous Malformations. Turk Neurosurg. 2016; 26(3): 341-346, doi: 10.5137/1019-5149.JTN.9190-13.1, indexed in Pubmed: 27161458.

63. Suzuki H, Maki H, Taki W. Evaluation of cerebral arteriovenous malformations using image fusion combining three-dimensional digital subtraction angiography with magnetic resonance imaging. Turk Neurosurg. 2012; 22(3): 341-345, doi: 10.5137/1019-5149.JTN.5527-11.0, indexed in Pubmed: 22665003.

64. Takahashi S. Intracranial arterial system: basal perforating arteries. In: Neurovascular imaging. MRI and microangiography. Springer, London 2010: 55-130.

65. Tamaki M, Ohno K, Asano T, et al. Cryptic arteriovenous malformation of the choroid plexus of the fourth ventricle--case report. Neurol Med Chir (Tokyo). 1994; 34(1): 38-43, indexed in Pubmed: 7514753.
66. Tatu L, Moulin T, Bogousslavsky J, et al. Arterial territories of human brain: brainstem and cerebellum. Neurology. 1996; 47(5): 1125-1135, indexed in Pubmed: 8909417.

67. Tatu L, Moulin T, Bogousslavsky J, et al. Arterial territories of the human brain: cerebral hemispheres. Neurology. 1998; 50(6): 1699-1708, indexed in Pubmed: 9633714.

68. Taveras JM. Neuroradiology. 3rd Ed. Williams \& Wilkins. A Waverly Company, Baltimore 1996: 1-1190.

69. Tsukahara T, Regli L, Hänggi D, Turowski B, Steiger HJ. Trends in neurovascular surgery. Springer, Wien 2011: 1-142.

70. Tsutsumi K, Shiokawa Y, Kubota M, et al. [A case of large basal ganglia AVM totally removed by staged operation]. No Shinkei Geka. 1990; 18(9): 871-876, indexed in Pubmed: 2234310.

71. Uchino A, Kato A, Abe M, et al. Association of cerebral arteriovenous malformation with cerebral arterial fenestration. Eur Radiol. 2001; 11(3): 493-496, doi: 10.1007/ s003300000640, indexed in Pubmed: 11288858.

72. Umansky F, Juarez SM, Dujovny $M$, et al. Microsurgical anatomy of the proximal segments of the middle cerebral artery. J Neurosurg. 1984; 61(3): 458-467, doi: 10.3171/ jns.1984.61.3.0458, indexed in Pubmed: 6747682.

73. Viñuela F, Duckwiler G, Jahan R, et al. Therapeutic management of cerebral arteriovenous malformations. Present role of interventional neuroradiology. Interv Neuroradiol. 2005; 11(Suppl 1): 13-29, doi: 10.1177/1591019905011 OS104, indexed in Pubmed: 20584455.

74. Westermaier T, Linsenmann T, Keupp M, et al. Fourth Ventricular AVM with Transdural Drainage. J Neurol Surg A Cent Eur Neurosurg. 2017; 78(2): 206-209, doi: 10.1055/s-0035-1563557, indexed in Pubmed: 26935294.

75. Yamada K, Mase M, Matsumoto T. Surgery for deeply seated arteriovenous malformation: with special reference to thalamic and striatal arteriovenous malformation. Neurol Med Chir (Tokyo). 1998; 38 Suppl: 227-230, indexed in Pubmed: 10235010.

76. Yasargil MG, Smith RD, Young PH, Teddy PJ. Microneurosurgery. Microsurgical anatomy of the basal cisterns and vessels of the brain, diagnostic studies, general operative techniques and pathological considerations of the intracranial aneurysms. Vol 1. Georg Thieme Verlag, Stuttgart 1984: 1-371.

77. Yasargil MG, Smith RD, Young PH, Teddy PJ. Microneurosurgery. Clinical considerations, surgery of the intracranial aneurysms and results. Vol 2. Georg Thieme Verlag, Stuttgart 1984: 1-386.

78. Yasargil MG, Teddy PJ, Valavanis A. AVM of the brain, history, embryology, pathological considerations, hemodynamics, diagnostic studies, microsurgical anatomy. Vol 3A. Georg Thieme Verlag, Stuttgart 1986: 1-408.

79. Yen CP, Steiner L. Gamma knife surgery for brainstem arteriovenous malformations. World Neurosurg. 2011; 76(1-2): 87-95; discussion 57, doi: 10.1016/j.wneu.2011.02.003, indexed in Pubmed: 21839958.

80. Young AMH, Teo M, Martin SC, et al. The diagnosis and management of brain arteriovenous malformations in a single regional center. World Neurosurg. 2015; 84(6): 1621-1628, doi: 10.1016/j.wneu.2015.06.017, indexed in Pubmed: 26100164. 